\title{
Olfactory dysfunction as a marker of multiple sclerosis progression
}

Distúrbios do olfato como marcadores de progressão na esclerose múltipla

Maria Lucia Vellutini Pimentel ${ }^{1,2}$

'Santa Casa de Misericórdia do Rio de Janeiro, Ambulatório de Doenças Desmielinizantes, Rio de Janeiro RJ, Brasil;

${ }^{2}$ Escola Médica de Pós-Graduação da PUC-RJ, Rio de Janeiro RJ, Brasil.

Correspondence:

Maria Lucia Vellutini Pimentel;

Rua Garcia D'Avila, 64 / sala 402;

22421-010 Rio de Janeiro RJ, Brasil;

E-mail:mlvpimentel@gmail.com

Conflict of interest:

There is no conflict of interest to declare.

Received 20 August 2016 Accepted 27 August 2016

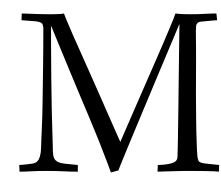

ultiple sclerosis (MS) is a demyelinating and degenerative disease of the central nervous system affecting especially young people, leading to neurological disability and impacting their quality of life. It is a multifaceted disorder, which means a unique disease in each patient. Symptoms that are more frequent and more disabling as motor impairment, incoordination, visual deficit and urinary disorder draw the attention of doctors and patients alike. Meanwhile other symptoms can cause more embarrassment in the MS patients daily life like cognition deficit, sexual disabilities and olfactory dysfunction, which do not have a proper evaluation. Although not well considered, olfaction is essential in everyday activities. The lack of awareness of olfactory deficit in MS patients can underestimates this disorder, which can indicate a subclinical neurodegenerative process.

MS patients rarely report smell changes, therefore olfaction was considered to be relatively preserved in $\mathrm{MS}^{1}$. However, different studies ${ }^{2,3,4,5}$ suggested olfactory loss in those patients but it remains unclear if it is an early symptom of MS as it is in other neurodegenerative diseases as Parkinson's disease, Alzheimer's disease and Huntigton's disease ${ }^{6,7}$.

The incidence of olfaction in MS is variable. Different trials found an incidence of $15 \%$, $22 \%$ and $38.5 \%$ when compared to healthy controls ${ }^{3.89}$. In a recent systematic review of the literature $^{10}$ searching for olfactory dysfunction in MS patients, forty articles were analyzed and pointed out a variability in reported frequency, but suggested a prevalence of olfactory dysfunction in $20 \%$ to $45 \%$ of MS population. The disagreement among investigators may arise from different testing methods, small size of the samples, heterogeneity of the study design but it can also be influenced by corticosteroid treatment as smell function can improve during remission and worsen during relapses.

Although olfactory impaired function in MS and the inability to identify odor were associated to anxiety, depression and to the degree of neurological incapacity ${ }^{9}$, in several studies $^{11,12,13}$, this association was not found when assessing different qualities of olfaction such as the ability to detect odor threshold, the ability to identify and discriminate the odors. Moreover, each quality of olfaction was related to a different phase of the disease. A worse olfactory threshold was observed in the early inflammatory phases while an identification score was more impaired in the widespread chronic disease. This could be explained by smell threshold being part of the more peripheral regions of the olfactory system while the ability to discriminate and identify odors are attributed to several damaged areas of the brain. When analyzing demyelinating plaques in brain MRI of MS patients ${ }^{2-5}$, the inferior frontal- and temporal-lobe regions, which are involved in olfaction, had a negative relation with smell dysfunction. Considering other brain regions not concerned to olfaction, the number of plaques did not have such relation. Olfactory bulb tract axonal loss was reported in 12 out of 17 MS patients ${ }^{14}$ and related to the extension of demyelination in brain, especially in the inferior frontal cortex, although other areas beyond the orbitofrontal cortex are involved in the perception and processing of different odorants, as the insula, cerebellum, visual and cingulate cortex. Therefore, olfactory dysfunction could be an early indication of disease progression, and a marker of widespread disease in the brain.

In this issue of Arquivos de Neuro-Psiquiatria Jordy et al. ${ }^{15}$ emphasize olfaction dysfunction as a measure of MS disease activity and progression. In a controlled cross-sectional study 
they evaluated $100 \mathrm{MS}$ patients using the Connecticut test (CCCRC) to verify the correlation among disease duration, EDSS (Expanded Disability Status Scale) and olfactory dysfunction. They found olfactory dysfunction in $32 \%$ of MS patients and this incapacity was more frequent in patients over 38 years old, those with an EDSS above 4.0 and with a longer disease duration. In another robust study ${ }^{16}$, in a sample of 153 MS patients the authors also observed olfactory dysfunction in older MS patients. Although they found $11.1 \%$ of MS patients with olfaction identification dysfunction compared to a health control group (3\%), this dysfunction was higher in secondary progressive MS (SPMS) (68.8\%) than in relapsing-remitting multiple sclerosis (RRMS) (3.3\%) also demonstrating the correlation between olfactory dysfunction and longer disease duration. The dynamic changes in olfactory function in the course of MS must be better understood.

In summary, Jordy et al demonstrate that olfaction evaluation in MS patients demands more attention and olfactory dysfunction can be an important tool in the follow-up of MS patients but warrants further research to better understanding of the relationship between olfaction dysfunction and clinical exacerbations. Their results were in accordance with the literature ${ }^{4,9,11,16}$ correlating olfactory dysfunction with higher EDSS and longer diagnosis duration. The data gathered could be used in the future to monitor the disease and the response to treatment as in the development of clinical markers to confirm or even predict disease progression in RRMS patients.

\section{References}

1. Lumsden CE. The neuropathology of multiple sclerosis. In: Vinken PJ, Bruyn GW, eds. Handbook of clinical neurology. New York: Elsevier; 1970. p. 217-309.

2. Doty RL, Li C, Mannon LJ, Youssem DM. Olfactory dysfunction in multiple sclerosis. N Eng J Med, 1997;336(26):1918-9. doi:10.1056/NEJM199706263362617

3. Doty RL, Li C, Mannon LJ, Yousem DM. Olfactory dysfunction in multiple sclerosis. Relation to plaque load in inferior frontal and temporal lobes. Ann NY Acad Sci. 1998; 8551 OLFACTION AND:781-6. doi:10.1111/j.1749-6632.1998.tb10658.x

4. Zorzon M, Ukmar M, Bragadin LM, Zanier F, Antonello RM, Cazzato G et al. Olfactory dysfunction and extent of white matter abnormalities in multiple sclerosis: a clinical and MR study. Mult Scler. 2000;6(6):386-90. doi:10.1177/135245850000600605

5. Erb K, Bohner G, Harms L, Goektas O, Fleiner F, Dommes E et al. Olfactory function in patients with multiple sclerosis: a diffusion tensor imaging study. J Neurol Sci, 2012;316(1-2):56-60. doi:10.1016/j.jns.2012.01.031

6. Singh S, Schwankhaus J. Olfactory disturbance in Parkinson's disease. Arch Neurol 2009;66(6):805-6. doi:10.1001/archneurol.2009.87

7. Barresi M, Ciurleo R, Giacoppo S, Foti Cuzzola V, Celi D, Bramanti P et al. Evaluation of olfactory dysfunction in neurodegenerative diseases. J Neurol Sci. 2012;323(1-2):16-24. doi:10.1016/j.jns.2012.08.028

8. Hawkes $\mathrm{CH}$, Shephard BC. Olfactory evoked responses and identification tests in neurological disease. Ann NYAcad Sci. 1998;855 1 OLFACTION AND:608-15. doi:10.1111/j.1749-6632.1998.tb10631.x
9. Zivadinov R, Zorzon M, Monti Bragadin L, Pagliaro G, Cazzato G. Olfactory loss in multiple sclerosis. J Neurol Sci. 1999;168(2):127-30. doi:10.1016/S0022-510X(99)00189-6

10. Lucassen EB, Turel A, Knehans A, Huang X, Eslinger P. Olfactory dysfunction in multiple sclerosis: a scoping review of the literature. Mult Scler Relat Disord. 2016;6:1-9. doi:10.1016/j.msard.2015.12.002

11. Lutterotti A, Vedovello M, Reindl M, Ehling R, DiPauli F, Kuenz B et al. Olfactory threshold is impaired in early, active multiple sclerosis. Mult Scler. 2011;17(8):964-9. doi:10.1177/1352458511399798

12. Rolet A, Magnin E, Millot JL, Berger E, Vidal C, Sileman G et al. Olfactory dysfunction in multiple sclerosis: evidence of a decrease in different aspects of olfactory function. Eur Neurol. 2013;69(3):166-70. doi:10.1159/000345482

13. Caminiti F, De Salvo S, De Cola MC, Russo M, Bramanti P, Marino $S$ et al. Detection of olfactory dysfunction using olfactory event related potentials in young patients with multiple sclerosis. PLoS One. 2014;9(7):e103151. doi:10.1371/journal.pone.0103151

14. DeLuca GC, Joseph A, George J, Yates RL, Hamard M, Hofer $M$ et al. Olfactory pathology in central nervous system demyelinating diseases. Brain Pathol. 2015;25(5):543-51. doi:10.1111/bpa.12209

15. Jordy SS, Starzewski Junior A, Macedo FAB, Manica GR, Tilber CP, Carabetta EG. Olfactory alterations in patients with multiple sclerosis. Arq Neuropsiquiatr. 2016;74(9):697-700. doi:10.1590/0004-282X20160128

16. Silva AM, Santos E, Moreira I, Bettencourt A, Coutinho E, Goncalves A et al. Olfactory dysfunction in MS: association with secondary progression. Mult Scler. 2012;8(5):616-21. doi:10.1177/1352458511427156 